\title{
Research on Preference regarding Online Consumption Behavior towards Geographically Indicated Agricultural Products
}

\author{
Wang Chunying ${ }^{1, a}$ \\ ${ }^{1}$ Department of Economic Management, Jilin Agricultural Science and Technology University, Jilin City, Jilin Province, China
}

\begin{abstract}
Taking rice, people's staple food in most areas of China, as an example, this paper has searched relevant evaluation and literature of online stores specializing in geographically indicated agricultural products on those leading e-commerce platforms such as Taobao and Jingdong. The goal is to determine the main attributes considered by online consumers and apply conjoint analysis method to analyzing the significance level of each attribute when they purchase geographically indicated rice. It is indicated that online marketing of geographically indicated agricultural products entails identifying consumer characteristics and the orientation, while product distributors and industry associations should build a sound and traceable system of agricultural products to enhance consumers' trust.
\end{abstract}

\section{Introduction}

Despite the unique quality thanks to their specific geographical origins, many geographically indicated agricultural products in remote areas are under the restrictions of small scale and producers' lack of business philosophy, making it impossible for these special agricultural products to transform their quality advantage into benefit of scale economies. Recent years have seen related policies introduced by the Chinese government to support and facilitate the development of rural ecommerce with the aim of maximizing the output value of geographically indicated agricultural products; nevertheless, online marketing of agricultural products differs from other types of products on issues ranging from expiration date to logistics efficiency and to food security. In the business mode of e-commerce certain short-term economic benefits can be realized by enabling sellers and purchasers of agricultural products on specific platform to reach agreements on and complete the payments for special agricultural products displayed on the Internet to consumers before distributing agricultural products through logistics. Despite that, challenges remain concerning how to sustain such benefits as long as possible so as to win customers' trust in particular geographically indicated agricultural products and absorb them into the circle of loyal customers. To realize that, it is required to identify based on the preference of online consumers' behavior what factors will earn customers' trust before they are willing to place an order when they purchase agricultural products on e-commerce platforms, to pinpoint the ones among the above mentioned factors that mainly effect customers' willingness to buy, and to figure out the reasons behind. Online marketing strategy should also be improved based on the information dissemination features of online shopping platforms selling geographically indicated agricultural products. Therefore, this research clarifies the significant attributes and their corresponding levels that consumers are concerned about during purchasing such kind of agricultural products in accordance with evaluation posted on e-commerce platforms after the sales of rice, and clarifies their significance levels and underlying reasons through questionnaires and in-depth interviews, so as to provide a reference for improving strategy for online marketing of geographically indicated agricultural products.

\section{Literature Review}

Rural e-commerce has been developing rapidly. Compared with other products, agricultural products possess striking characteristics in logistics, online marketing mode and consumers' behavior of online shopping, which have attracted a number of scholars' attention. Among those scholars, Wang Hong and Sun Yuling (2019) systematically analyzed the omni-channel retail mode applied to the supply chain of fresh agricultural products in the background of "Internet Plus"; Zhao Shuai, Li Yacheng and some other scholars (2019) analyzed the development mode as well as the upgrading and reconstruction of platform-based enterprises with "Dounan Flower Industry Group" as an example; research on behavior of shopping agricultural products online mainly centered on analyzing influence factors, perceived risk, consumers' trust and degree of satisfaction, whereas research on behavior of purchasing geographically indicated agricultural products online mainly concentrated on brand building (Hou Yan, 2016), consumers' willingness to buy, and influence factors (Shang Xudong included, 2014). A process of awareness and cognition 
exists before customers purchase geographically indicated agricultural products. Lei Yue (2011), after reviewing scholars' research in copious literature, indicated that consumers' awareness and recognition of certain products and their brands were rooted in previous contact, by which consumers accessed more brand information either passively or positively, which further influenced or shaped brand preference. Bai Shizhen and some other scholars (2017) demonstrated in their research on the cognitive process of green agricultural products that more contact and experience with knowledge and logos of green agricultural products contributed to customers' stronger awareness about green agricultural products and a higher level of recognition, even further making customers inclined to buy green agricultural products at a premium. The process of product contact during online consumption remains more indispensable to customers' awareness about agricultural products. Customers will generate a preliminary understanding of certain agricultural products based on purchase experience from other customers, related establishedations of agricultural products, certifications and pricing information, and then integrate, process and evaluate the accessed information in the cognitive process before shaping preference regarding personal attitude.

\section{Research Design}

To have a clearer notion of consumers' considerations as well as the corresponding significance level when they purchase geographically indicated agricultural products on the Internet, this paper summarizes the main factors and attributes considered and evaluated in the case of purchasing geographically indicated rice, by taking rice as an example and analyzing related literature and comments posted on leading online marketing platforms. A questionnaire of preference as to purchasing geographically indicated rice online is designed on the basis of those main factors and attributes as well as their correlation. Conjoint analysis is applied to revealing the significance level of each factor and their order of priority.

\subsection{Determination of Considerations regarding Online Purchasing of Geographically Indicated Agricultural Products}

This research has selected and encoded 569 online shopping comments that appear relatively more valuable after screening comments on stores selling rice from early 2016 to late 2019 on the three leading platforms of Tmall, Jingdong and Suning. Among the 569 comments, 178 refer to taste, 165 to price, 148 refer to packaging, 124 to place of origin, 85 to logistics, 78 to repurchase, 79 to freshness, and 56 to service attitude. A comprehensive analysis on the comments and related literature demonstrated that the main considerations when consumers purchase geographically indicated rice prove to be price, quality, geographically indicated agricultural products, logistics quality and service quality. The attributes and their corresponding levels considered during purchasing geographically indicated rice is eventually described as shown in Table 1.

Table1. The attributes and levels considered by consumers during purchasing rice online

\begin{tabular}{|c|c|c|}
\hline attributes & levels & No. \\
\hline price & $\begin{array}{l}\text { on the high side } \\
\text { moderate } \\
\text { on the low side }\end{array}$ & $\begin{array}{l}1 \\
2 \\
3\end{array}$ \\
\hline quality & $\begin{array}{l}\text { high } \\
\text { medium } \\
\text { low }\end{array}$ & $\begin{array}{l}1 \\
2 \\
3\end{array}$ \\
\hline $\begin{array}{l}\text { brand awareness of } \\
\text { geographical indication }\end{array}$ & $\begin{array}{l}\text { established } \\
\text { devoid }\end{array}$ & $\begin{array}{l}1 \\
2\end{array}$ \\
\hline logistics service & $\begin{array}{l}\text { good } \\
\text { medium } \\
\text { poor }\end{array}$ & $\begin{array}{l}1 \\
2 \\
3 \\
\end{array}$ \\
\hline service quality & $\begin{array}{l}\text { high } \\
\text { medium } \\
\text { low }\end{array}$ & $\begin{array}{l}1 \\
2 \\
3\end{array}$ \\
\hline
\end{tabular}

\subsection{Profile Simulation of Purchasing Geographically Indicated Rice Online}

The profile of purchasing products online can be determined in accordance with the above mentioned product evaluation and related literature research as well as the attributes and levels considered by consumers during purchasing geographically indicated agricultural products. This research adopts full-profile approach to determine the main considerations during purchasing geographically indicated agricultural products on the Internet. The attributes and levels listed in Table 1 generate 162 types of combined modes of purchasing products online. To highlight reestablishedative combined simulation modes, this research has ultimately singled out 16 typical modes of purchasing products online for the questionnaire with the aid of conjoint analysis method, the statistical software SPSS21.0, and orthogonal experimental design. The questionnaire consists of basic information and simulated profile of purchasing rice online, in the latter of which 5-point Likert scale is utilized to measure the willingness to purchase online in 16 cases. The forms of establishedation have been adjusted after comparing the pre-research of 20 questionnaires. Price has its three grades expressed as RMB 20 yuan, 12 yuan and 3 yuan per catty (a catty $=0.5 \mathrm{~kg}$ ). Quality is described from three aspects including taste, fragrance and packaging. Awareness of geographically indicated agricultural products is reflected by Wuchang rice (produced in the county-lelvel city of Wuchang, Jilin) and Shulan rice (produced in Shulan City, Jilin) instead of brand awareness being devoid or established. Logistics service is specifically described with delivery speed and packaging intactness. In doing so the questionnaire proves easier to understand. 
Table2. Design of simulated profile of purchasing rice online

\begin{tabular}{|c|c|c|c|c|c|}
\hline $\begin{array}{l}\text { numbe } \\
\text { r on } \\
\text { the } \\
\text { card }\end{array}$ & price & quality & $\begin{array}{c}\text { brand } \\
\text { awareness } \\
\text { of } \\
\text { geographic }\end{array}$ & $\begin{array}{c}\text { logistic } \\
\mathrm{s} \\
\text { service }\end{array}$ & $\begin{array}{l}\text { service } \\
\text { quality }\end{array}$ \\
\hline 1 & moderat & high & devoid & poor & high \\
\hline 2 & $\begin{array}{l}\text { e } \\
\text { high }\end{array}$ & $\begin{array}{l}\text { mediu } \\
\mathrm{m}\end{array}$ & established & poor & low \\
\hline 3 & $\begin{array}{l}\text { moderat } \\
\mathrm{e}\end{array}$ & high & established & $\begin{array}{l}\text { mediu } \\
\mathrm{m}\end{array}$ & low \\
\hline 4 & high & low & devoid & $\begin{array}{l}\text { mediu } \\
\mathrm{m}\end{array}$ & high \\
\hline 5 & high & $\begin{array}{l}\text { mediu } \\
\mathrm{m}\end{array}$ & devoid & $\begin{array}{l}\text { mediu } \\
\mathrm{m}\end{array}$ & high \\
\hline 6 & $\begin{array}{l}\text { moderat } \\
\mathrm{e}\end{array}$ & low & established & good & high \\
\hline 7 & low & low & devoid & good & low \\
\hline 8 & low & high & established & $\begin{array}{l}\text { mediu } \\
\mathrm{m}\end{array}$ & $\begin{array}{l}\text { mediu } \\
\mathrm{m}\end{array}$ \\
\hline 9 & high & high & devoid & good & $\begin{array}{l}\text { mediu } \\
\mathrm{m}\end{array}$ \\
\hline 10 & low & $\begin{array}{l}\text { mediu } \\
\mathrm{m}\end{array}$ & established & good & high \\
\hline 11 & low & high & devoid & poor & high \\
\hline 12 & $\begin{array}{l}\text { moderat } \\
\mathrm{e}\end{array}$ & $\begin{array}{l}\text { mediu } \\
\text { m }\end{array}$ & devoid & good & $\begin{array}{l}\text { mediu } \\
\text { m }\end{array}$ \\
\hline 13 & high & low & established & poor & $\begin{array}{l}\text { mediu } \\
\text { m }\end{array}$ \\
\hline 14 & high & high & devoid & good & low \\
\hline 15 & high & high & established & good & high \\
\hline 16 & high & high & established & good & high \\
\hline
\end{tabular}

\section{Data Collection and Statistical Analysis}

\subsection{Data Collection}

From September to late December of 2019, consumers who purchased rice online were invited to fill in 176 questionnaires for this research, of which 13 prove invalid. Therefore, the effective rate of questionnaires collected stands at $92.6 \%$, among which female and male consumers account for $63.8 \%$ and $36.2 \%$ respectively; consumers aged between 24 and 35, 36 and 45, 46 and 55, and above 55 amount to $70,67,19$ and 7 respectively; degree higher than bachelor's, bachelor's degree, associate degree and other degrees account for $17.8 \%, 46 \%, 12.3 \%$ and $23.9 \%$ respectively; in terms of occupation, freelancers or self-employed individuals account for $15.9 \%$, science educators and national public servants account for $11 \%$, workers in enterprises and public institutions account for $35.6 \%$, housewives account for 10.4, and other professionals account for $27.1 \%$. Data on samples' gender, age, education background and occupation corroborate the extensive range this survey covers, which proves the effectiveness of the data source. Meanwhile the above data reveal that among online consumers professional women account for a large proportion, who are inclined to consume rationally, attach great importance to particulars and product quality, and take more factors into more comprehensive consideration than male consumers.

\subsection{Statistical Analysis}

In this research a conjoint analysis on the reliable data of 163 questionnaires with the statistical software SPSS21 has yielded in Table 3 the significance level of each attribute and the utility value for one level of an attribute, and the coefficient between measured date and factual data The Pearson and Kendall correlation coefficient, respectively 0.968 and 0.979 , means that the simulated profile of the considerations during purchasing rice online possesses a high correlation between observed values and predicted values, and has a relatively high goodness of fit. The reasonable consistency of simulated profile of the considerations with the physical situation proves that such profile can effectively reflect customers' preference when they purchase geographically indicated rice. Additionally, descriptive statistical analysis demonstrates that a linear relationship exists between the two variables of price and quality, namely a higher utility arising from a lower price and better quality, whereas all the other are discrete variables. The significance level in Table 3 reveals that when customers purchase rice online, quality takes priority, followed by price, geographically indicated agricultural products and logistics before service quality is finally considered.

Table3. Weight of attributes considered during purchasing rice online

\begin{tabular}{c|c}
\hline attributes & weight \\
price & 24.354 \\
quality & 32.563 \\
$\begin{array}{c}\text { brand awareness of geographical } \\
\text { indication } \\
\text { segistics service }\end{array}$ & 18.635 \\
\hline
\end{tabular}

\section{Conclusion and Enlightenment}

\subsection{Conclusion}

Customers put quality as a major concern before price, place of origin, and the quality of logistics and other related services when purchasing the staple food, rice. Rice, one of dominating food products, has its quality evaluated mainly from the perspective of taste and quality safety that are under the influence of growing conditions, place of origin, water resources and cultivation techniques. Those rice brands that enjoy high brand awareness of geographical indication and have been previously purchased generally receive more recognition and a higher evaluation from customers, which enhances their trust in those brands and shapes their purchasing preference. Rice with a comparatively higher price will not prevent customers' willingness to buy at a premium as long as the 
rice is of high quality, good taste, easy to preserve and delicately packaged. Once a negative experience arises from logistics, part of the service environment in the entire purchasing process which has little influence on customers' preference, the product brand, enterprise brand and even geographically indicated brand will see their images negatively effected. Therefore, businesses are required to have their overall service quality improved in each aspect of the whole process of online shopping, and have their product brand and geographically indicated brand images maintained.

\subsection{Enlightenment}

In this research the enlightenment that follows from the above conclusion is that: Firstly, the quality of geographically indicated agricultural products must be guaranteed, and more efforts should be put into the training of online marketing and the cultivation and reserve of talents. Secondly, the product distributors of geographically indicated agricultural products need to have a clear notion of their target market and product positioning. Pursuit of product quality from customers who are willing to purchase geographically indicated agricultural products signifies their recognition of special products in specific place of origin. For that reason, product distributors should have their product packaging design, and the contents and means of information dissemination tailored in accordance with customers' characteristics. Thirdly, the publicity of brand image should be strengthened regarding geographically indicated agricultural products by conducting omni-channel marketing and improving the integrated marketing communication (IMC) between online and offline. In doing so, the brand awareness and reputation of geographically indicated agricultural products are expected to be enhanced. Lastly, a sound traceable system for geographically indicated agricultural products should be built and a reasonable rating standard should be formulated so that consumers will have unreserved trust in the products and the place of origin.

\section{Acknowledgment}

This paper is one of the interim results of "Strategy for Measuring and Promoting the Brand Image of Geographically Indicated Rice"(No.20190436, Jilin Agricultural Science and Technology University), a key university-level research project undertaken by Jilin Agricultural Science and Technology University; the project is funded by the Center for Industrial \& Economic Research on Speciality Agriculture, the Education Department of Jilin Province; this paper is also an interim result of the project to keep the discipline of business administration under key construction in Jilin Agricultural Science and Technology University.

\section{References}

1. Wang Hong, Sun Yuling. A Study of the Omnichannel Operational Model of Fresh Agricultural Products Supply Chain[J]. Industrial Engineering Journal.2019,22(06):74-79+199.

2. Zhao Shuai,Li Ya-cheng,Li Wen-li,Qin Kaida.Business Model Innovation and Internal Mechanism of Platform-based Enterprises:A Case Study of Dounan Flower Insdustry Croup[J].Journal of Management Case Studies,2019,12(02):192-209.

3. Hou Yan.Research on brand building strategy of agricultural products e-commerce under the concept of "consumer center"[J].Journal of Commercial Economics,2016(05): 48-50.

4. Shang Xu-dong, Hao Yanchi, Li Bing-Long.An Analysis on Payment Intention of Consumers to Geographical Indication Agricultural Products_-A Case Study of Yanchi Tan-sheep[J].Journal of Technical Economics \& Management,2014(01):123128.

5. Wu Chunya,Xia Zhying,Luo Weiping. Deviation Analysison Consumers' Willingness and Behavior of Purchasing Agricultural Products with Geographical Indications Online[J].Issues in Agricultural Economy,2019(05):110-120.

6. Lei Yue.Study on the Formation of Brand Preference[D]. North China University of Technology,2011.

7. Bai Shizhen,Zheng jia,Wu Rong.Empirical Analysis on cognition, premium intention and purchase behavior of green agricultural products[J].Journal of Commercial Economics,2017(06):171-173. 